Original Research Article

\title{
A randomised double blind placebo controlled trial to assess the efficacy and tolerability of short course of ornidazole in diarrhoea predominant irritable bowel syndrome
}

\author{
Preetha Jose $^{1 *}$, Narayanan P. V. ${ }^{2}$, Varghese Thomas $^{3}$
}

\begin{abstract}
${ }^{1}$ Department of Pharmacology, Government Medical College, Thrissur, Kerala, India ${ }^{2}$ Principal, Malabar Medical College, Modakkallur, Calicut, Kerala, India

${ }^{3}$ Consultant Gastroenterologist, Malabar Medical College, Modakkallur, Calicut, Kerala, India
\end{abstract}

Received: 13 September 2018 Accepted: 11 October 2018

\section{*Correspondence to:}

Dr. Preetha Jose,

Email: preethajkpo@gmail.com

Copyright: (C) the author(s), publisher and licensee Medip Academy. This is an openaccess article distributed under the terms of the Creative Commons Attribution NonCommercial License, which permits unrestricted noncommercial use, distribution, and reproduction in any medium, provided the original work is properly cited.

\begin{abstract}
Background: Irritable bowel syndrome is a common disorder affecting the general population. At present the treatment is mainly symptomatic as the pathophysiology is not clear. Abnormal flora especially small bowel bacterial over growth is considered as one of the causes. A short course of ornidazole is compared with placebo to assess its efficacy and tolerability in diarrhoea predominant irritable bowel syndrome.

Methods: This was a randomised double-blind placebo controlled trial done in the Departments of Gastroenterology and Pharmacology at Government Medical College, Calicut. Patients were randomly assigned to two groups to receive either ornidazole or Placebo. The baseline symptoms were recorded and graded to get a global symptom score. Patients assigned to ornidazole group received 500mg twice daily orally for 5 days and the control group received identical looking placebo tablets. The patients were reassessed every week for four weeks. The patients subjective global assessment of relief and global symptom score was recorded. Statistical analysis was done using Wilcoxon signed Rank test and Mann Whitney U test.

Results: This study was done in twenty patients with a mean age of 30 with comparable baseline characteristics and symptom scores $(\mathrm{p}=0.969)$. Ornidazole produced a highly significant reduction in the global symptom score $(\mathrm{p}<0.001)$ compared to placebo. It was maintained through the four weeks follow up. No serious adverse effects were reported. Two patients reported burning sensation in the stomach which was self limited.

Conclusions: Ornidazole is efficacious than placebo in controlling the symptoms of diarrhoea predominant irritable bowel syndrome and is well tolerated.
\end{abstract}

Keywords: Diarrhoea predominant irritable bowel syndrome, Global symptom score, IBS-D, Ornidazole, Placebo

\section{INTRODUCTION}

Irritable bowel syndrome is a functional bowel disorder characterised by abdominal discomfort or pain associated with disturbed defecation in the absence of any structural abnormality. It can be diarrhoea predominant (IBS-D), constipation predominant, irritable bowel syndrome with alternating stool pattern. ${ }^{1}$ At present the treatment of IBS is mainly symptomatic as the exact pathological basis is not identified. Different factors implicated in the pathogenesis are altered colonic and small bowel motility, visceral hypersensitivity, genetic predisposition, low grade inflammation and stress. ${ }^{2}$ Anti spasmodic anticholinergics are used based on the fact that IBS can be due to increased high amplitude propagated contractions. But efficacy is poor. ${ }^{3}$ Anti diarrhoeals decrease stool frequency. But do 
not improve abdominal pain and bloating. ${ }^{4}$ Serotonin receptor antagonists like Alosetron is efficacious. But it caused constipation and rarely ischemic colitis in some patients. ${ }^{3,5}$ Tricyclic antidepressants and anxiolytics are used. But adverse effects are common. ${ }^{6}$ There is some data to suggest that IBS-D can be due to abnormal intestinal flora resulting in increased colonic fermentation and production of excess gas. ${ }^{7}$ In a study conducted by Pimental et al, showed that small intestinal bacterial over growth is associated with IBS and that eradication of bacterial overgrowth eliminates IBS in $48 \%$ of the subjects. Anttimicrobilas like Rifaximin, Metronidazole and Neomycin were studied in IBS. They appear to be superior to placebo in short term treatment studies. ${ }^{8-10}$ Ornidazole is a newer 5 nitroimidazole antibiotic effective against pathogenic bacteria and protozoa in the GIT. ${ }^{11,12}$ Due to dearth of data we decided to do this study comparing ornidazole with placebo in IBS-D.

\section{METHODS}

This study compares the efficacy and tolerability of a short course of ornidazole in diarrhoea predominant irritable bowel syndrome (IBS-D). The study was designed as a double blind randomised comparative clinical trial. It was done after approval by the institutional ethics committee from March 2008 to March 2009. Patients were selected from the department of Gastroenterology, Government Medical College, Calicut. Patients above 18 years and below 60 years who satisfied the Rome III diagnostic criteria for diarrhoea predominant irritable bowel syndrome were included in the study. ${ }^{7}$ Patients who had colitis of any aetiology or other co-morbid conditions requiring concurrent medications; pregnant and lactating mothers were excluded from the study. Twenty four patients were recruited in to the study. The patients were randomly assigned in to two groups to receive either ornidazole or placebo. Written informed consent was taken from all patients after properly explaining about the study. Complete history was elicited which covered symptoms, duration of illness and the treatment history. Laboratory tests including complete hemogram, liver function test, renal function test, thyroid function test, stool routine, stool culture and sensitivity and stool occult blood was done to rule any organic cause. Of the twenty-four patients 1 patient was detected to have hyperthyroidism, 1 patient had whip worm ova in routine stool examination and 2 patients reported of taking antibiotics during the previous 1 month. They were excluded, and the rest were assigned in to two groups to receive ornidazole or placebo using computer generated random number table.

Patients assigned to the ornidazole group received 500mg twice daily after food for five days. Those in the placebo group received identical looking placebo tablets similarly. These patients were asked to take no other medication related to their present condition. Baseline symptoms were recorded and graded before treatment to get the global symptom score. The parameters considered for scoring were the frequency of bowel movements, consistency of stool, and additional characteristics like presence or absence of mucous, tenesmus and associated abdominal pain or bloating. The patients were reassessed every week for 4 weeks for symptom relief and global symptom score recorded. The patients subjective global assessment of relief scored as 1 - complete relief, 2 - moderate relief, 3 slight relief, 4 - no relief, 5 - worsening of symptoms was also recorded. The patients were asked to report immediately in case of any difficulty or untoward effects.

\section{Analysis of data}

Statistical analysis was done using Statistical package for social service (SPSS) software. Wilcoxon signed rank test and Mann Whitney $U$ test were done for the analysis of data. Results were tabulated, and significance was expressed according to the $\mathrm{p}$ value, $<0.05$ - significant and $<0.001$ - highly significant

\section{RESULTS}

A total of 20 patients with diarrhoea predominant irritable bowel syndrome who fulfilled the exclusion and inclusion criteria were selected from the department of gastroenterology, Government medical college, Calicut. They were randomly assigned in to two groups to receive either ornidazole $(n=10)$ or placebo $(n=10)$.

The comparison of baseline parameters including the Global symptom score (GSS) between the two groups is shown in Table 1. Mean global symptom score of the patients in the placebo group was 6.8 and that of the ornidazole group was 7.1 with $\mathrm{p}$ value 0.969 . The mean age of the patients was 31.8 in the placebo group and 28.9 in the ornidazole group. $60 \%$ of the patients were males and the rest females in the placebo group and $80 \%$ were males and the rest females in the ornidazole group. There was no significant difference between the two groups.

Table 1: Comparison of Baseline parameters of the placebo and ornidazole group.

\begin{tabular}{|lllcl|}
\hline & Placebo & Ornidazole & $\begin{array}{l}\text { Test } \\
\text { value }\end{array}$ & $\begin{array}{l}\text { P } \\
\text { value }\end{array}$ \\
\hline $\begin{array}{l}\text { Baseline } \\
\text { GSS }\end{array}$ & $6.8 \pm 1.62$ & $7.10 \pm 2.20$ & 49.5 & 0.969 \\
\hline Age & $31.8 \pm 11.72$ & $28.9 \pm 9.3$ & 0.60 & 0.556 \\
\hline Sex & $\begin{array}{l}\text { Male } 60 \% \\
\text { Female } 40 \%\end{array}$ & $\begin{array}{l}\text { Male } 80 \% \\
\text { Female 20\% }\end{array}$ & 0.952 & 0.329 \\
\hline
\end{tabular}

Table 2 compares the reduction in global symptom score after treatment at the $1^{\text {st }}, 2^{\text {nd }}, 3^{\text {rd }}$ and $4^{\text {th }}$ week follow up between ornidazole and placebo groups. The reduction in mean global symptom score was 0.8 in the placebo group while it was 5.3 in the ornidazole group with a $\mathrm{p}$ value of $<0.001$. There was highly significant reduction in the global symptom score in ornidazole group compared to the placebo group which was maintained at the $2^{\text {nd }} 3^{\text {rd }}$ and $4^{\text {th }}$ week follow up. 
Table 2: Global Symptom Score analysis after treatment.

\begin{tabular}{|c|c|c|c|}
\hline Visits & Placebo & Ornidazole & $\begin{array}{l}\text { Mann Whitney } \\
\text { U, p value }\end{array}$ \\
\hline $\mathrm{GS}_{0-1}$ & $0.8 \pm 1.229$ & $5.3 \pm 1.828$ & $2.0,<0.001$ \\
\hline $\mathrm{GS}_{0-2}$ & $0.9 \pm 1.2867$ & $5.4 \pm 1.7127$ & $2.0,<0.001$ \\
\hline $\mathrm{GS}_{0-3}$ & $1.1 \pm 1.2867$ & $5.5 \pm 2.2236$ & $3.0,<0.001$ \\
\hline $\mathrm{GS}_{0-4}$ & $1.4 \pm 1.8135$ & $5.8 \pm 1.8135$ & $1.0,<0.001$ \\
\hline
\end{tabular}

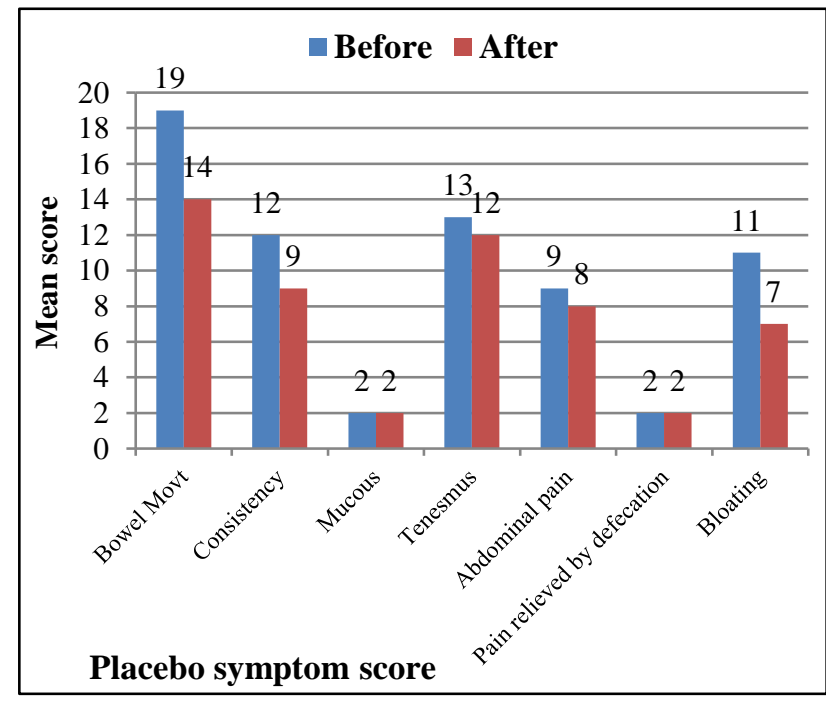

Figure 1: Symptom scores before and after treatment - Placebo group.

The individual scores of the parameters considered to get the global symptom score before treatment is compared with that after treatment. In the placebo group there is only very little improvement in the frequency of bowel movements, consistency of stools, abdominal pain, tenesmus and bloating. There is no improvement in the mucous content in the stools.

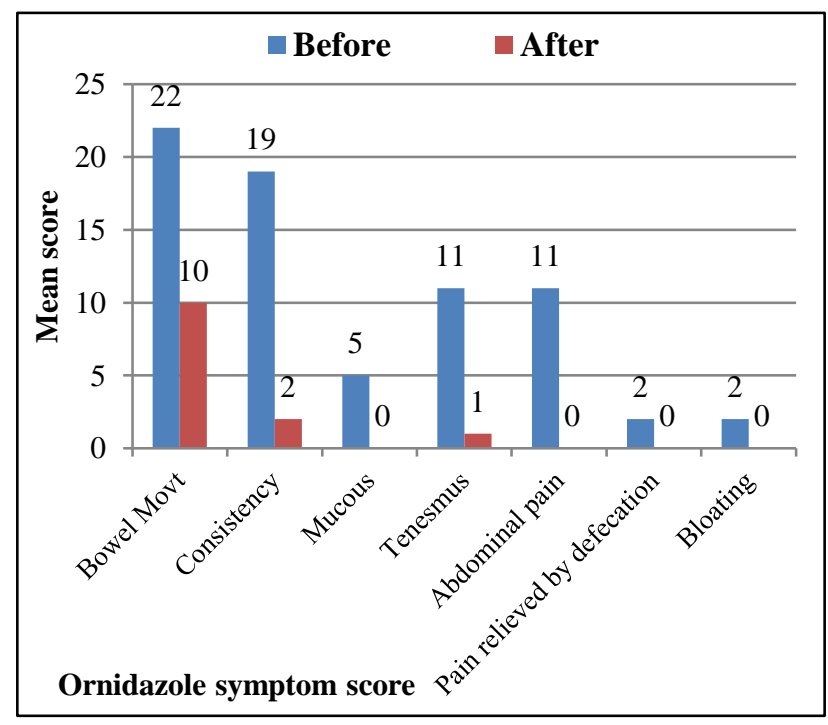

Figure 2: Symptom scores before and after treatment - ornidazole group.
Figure 2 shows the comparison between the individual scores of the parameters considered to get the global symptom score in the ornidazole group before and after treatment. There is significant improvement in the frequency of bowel movements and consistency of stools with no mucous, associated abdominal pain or bloating.

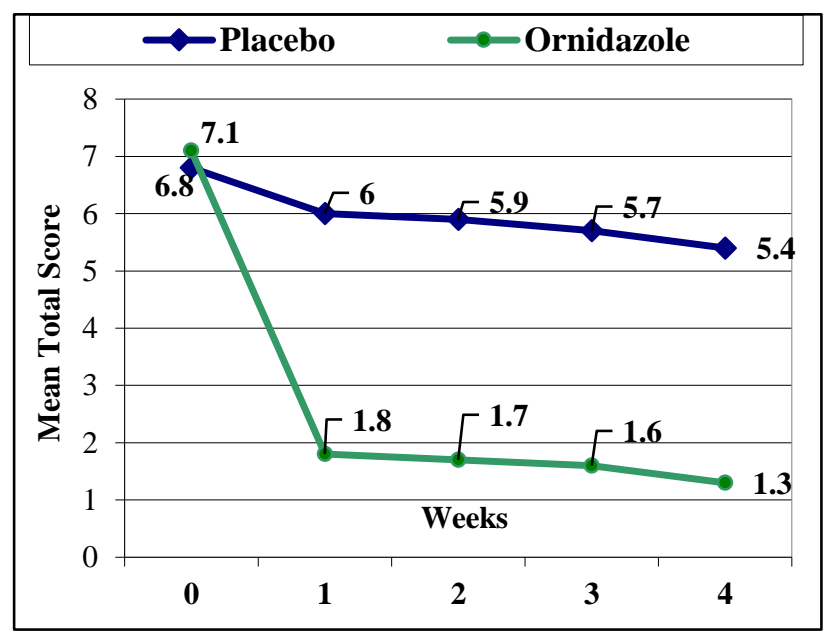

Figure 3: Mean global symptom Score at baseline and weekly follow ups.

Figure 3 compares the mean global symptom scores of the ornidazole and Placebo group. There is a steep fall in the mean global symptom score in the ornidazole group from 7.1 to 1.8 after treatment and it was maintained during the study period. The fall in the mean global symptom score (from 6.8 to 6 ) in the placebo group is less marked.

Table 3: SGA- Subjective Global Assessment of relief after treatment.

\begin{tabular}{|c|c|c|c|c|c|}
\hline & Drug & Mean & $\begin{array}{l}\text { Std. } \\
\text { deviation }\end{array}$ & $\begin{array}{l}\text { Mann. } \\
\text { Whitney }\end{array}$ & $\begin{array}{l}\text { Asymp. } \\
\text { Sig. } \\
2 \text { tailed }\end{array}$ \\
\hline \multirow{2}{*}{$\mathrm{SGA}_{1}$} & Placebo & 3.40 & 0.84 & \multirow{2}{*}{5.000} & \multirow{2}{*}{0.000} \\
\hline & Ornidazole & 1.50 & 0.53 & & \\
\hline \multirow{2}{*}{$\mathrm{SGA}_{2}$} & Placebo & 3.40 & 070 & \multirow{2}{*}{2.000} & \multirow{2}{*}{0.000} \\
\hline & Ornidazole & 1.40 & 0.52 & & \\
\hline \multirow{2}{*}{$\mathrm{SGA}_{3}$} & Placebo & 3.20 & 0.79 & \multirow{2}{*}{5.000} & \multirow{2}{*}{0.000} \\
\hline & Ornidazole & 1.50 & 0.53 & & \\
\hline \multirow{2}{*}{$\mathrm{SGA}_{4}$} & Placebo & 2.90 & 0.88 & \multirow{2}{*}{6.000} & \multirow{2}{*}{0.000} \\
\hline & Ornidazole & 1.30 & 0.48 & & \\
\hline
\end{tabular}

The subjective global assessment (SGA) of relief after treatment at the $1^{\text {st }}, 2^{\text {nd }}, 3^{\text {rd }}$ and $4^{\text {th }}$ week follow up in both groups is compared in Table 3. The patients in the ornidazole group had significant reduction in the symptoms and gave significant reduction in SGA scores. The mean SGA score was 1.5 after 1 week and 1.4, 1.5 and 1.3 respectively at $2^{\text {nd }}, 3^{\text {rd }}$ and $4^{\text {th }}$ week follow up. In the placebo group mean SGA score was 3.4, 3.4, 3.2 and 2.9. Ornidazole was found to reduce the SGA score more than placebo. The $\mathrm{p}$ value is $<0.001$ consistently. 
Two patients who were given ornidazole complained of burning sensation in the stomach and dyspepsia which subsided without any intervention after the course of ornidazole. Causality assessment as per Naranjo scale was found to be possible.

\section{DISCUSSION}

Irritable Bowel Syndrome is a fairly common disease which is not fatal nor linked to the development of any serious bowel disease. But it is important due to its high prevalence and morbidity. As specific pathological basis for the symptoms are not clearly identified treatment is mainly symptomatic. Data from some studies suggest that IBS-D can be due to abnormal intestinal bacterial overgrowth resulting in production of excess gas. ${ }^{7,8} \mathrm{We}$ can address this problem by using antibiotics and probiotics. With probiotics the results are not consistent. ${ }^{13}$ This study is a randomised double blind placebo controlled trial to assess the efficacy and tolerability of ornidazole in diarrhoea predominant irritable bowel syndrome. ornidazole is a newer nitroimidazole antibiotic and the efficacy of this drug in IBS-D has not been studied so far. It is effective against anaerobic microorganisms and protozoa.

It is used in the treatment of susceptible protozoal infections and for the treatment and prophylaxis of anaerobic infections. ornidazole has a longer $t 1 / 2$ and is better tolerated than Metronidazole which is the more commonly used nitroimidazole antibiotic. ${ }^{10,11}$

Base line parameters of both groups were compared with $\mathrm{p}$ value $>0.05$. On assessing the efficacy of ornidazole, it produced significant reduction in the global symptom score at 1 week and relief as per subjective global assessment of relief. This was maintained at 2 weeks, 3 weeks and 4 weeks follow up. Even though there is reduction in global symptom score in both groups, compared to placebo ornidazole produced a highly significant reduction in symptom score at 1 week, 2 weeks, 3 weeks and 4 weeks in comparison. As far as the tolerability is concerned no serious adverse effects were reported after administering ornidazole or placebo. Two patients who were given ornidazole complained of burning sensation in the stomach and dyspepsia which subsided without any intervention after the course of ornidazole. The causality assessment as per Naranjo scale was found to be possible. ${ }^{14}$

As per this study ornidazole is found to be more effective than placebo in treating diarrhoea predominant irritable bowel syndrome and it is well tolerated. The efficacy of this drug in diarrhoea predominant irritable bowel syndrome (IBS-D) has not been studied. Diarrhoea predominant irritable bowel syndrome (IBS-D) is a chronic disease. In this study follow up is done only for 4 weeks. Long term follows up involving more number of patients has to be done to see if the improvement in the symptoms is persistent to establish the efficacy of ornidazole conclusively.

\section{CONCLUSION}

Diarrhoea predominant irritable bowel syndrome is a prevalent disease in the population characterised by abdominal pain and changes in bowel habits. It is not associated with any abnormalities in routine clinical tests. Different mechanisms are implicated in the pathology of IBS-D. There is some evidence to suggest that IBS-D can be due to abnormal colonic flora causing inflammation and increased colonic fermentation. Ornidazole is a nitroimidazole antibiotic which is effective against colonic bacteria and many protozoa which can address this problem. This study was under taken to compare the efficacy and tolerability of ornidazole against placebo in diarrhoea predominant irritable bowel syndrome and is the first of its kind. Ornidazole was well tolerated. No significant adverse effects were reported except complaints of burning sensation in the stomach which was reported by two patients on ornidazole. It was self limited. Both ornidazole and placebo were found to produce a significant reduction in the total symptom score and improvement in subjective global assessment of relief. But ornidazole was found to have better efficacy compared to placebo in relieving symptoms when both results were compared using Mann Whitney U test $(\mathrm{p}<0.001)$. The improvement in the symptoms with ornidazole is also maintained throughout the four weeks of follow up.

Funding: No funding sources

Conflict of interest: None declared

Ethical approval: The study was approved by the Institutional Ethics Committee

\section{REFERENCES}

1. Longstreth GL, Thompson WG, Chey WD, Houghton LA, Mearin F, Spiller RC. Functional bowel disorders, Gastroenterology. 2006;130:1480-91.

2. Drossman D, Camilleri M, Mayer E, Whitehead WE. AGA technical review on irritable bowel syndrome. Gastroenterology. 2002;123:2108.

3. Brandt LJ, Bjorkman D, Fennerty MB, Locke GR, Olden K, Peterson W, et al. Systematic review on the management of irritable bowel syndrome in North America. Ame J Gastroenterol. 2002;97(Suppl):S7S26.

4. Drossman DA. The functional gastrointestinal disorders and the Rome III process. Gastroenterology. 2006;130(5):1377-90.

5. Rahimi R, Nikfar S, Abdollahi M. Efficacy and tolerability of Alosetron for the treatment of Irritable bowel syndrome in women and men. Ameta analysis of 8 randomised placebo controlled, 12 week trials Clinical Therapeutics. 2008;30(5):884-901.

6. Sleisenger and Fodtran's Gastrointestinal and liver disease. Mark Feldman, Lawrence. S. Friedman and 
Lawrence, J. Brandt. 8th ed. Saunders, Philadelphia; 2006;2:2645.

7. Madden JAJ, Hunter JO. A review of the role of the gut flora in irritable bowel syndrome and effects of probiotics. British Journal of Nutrition. 2002;88 (Suppl1):S67-S72.

8. Pimentel M, Chow EJ, Lin HC. Eradication of small intestinal bacterial overgrowth reduces symptoms of irritable bowel syndrome. Ame J Gastroenterol. 2000;95(12):3504-6.

9. Pimentel M, Park S, Mirocha J, Kane S, Kong, Y. The effect of a nonabsorbed oral antibiotic (rifaximin) on the symptoms of the irritable bowel syndrome: a randomized trial. Ann Intern Med. 2006;145:557-63.

10. Pimentel M, Chow EJ, Lin HC. Normalisation of lactulose breath testing correlates with symptom improvement in irritable bowel syndrome. A double blind randomized placebo controlled study. American J Gastroenterol. 2003;98(2):412-9.

11. Tripathi KD. Essentials of Medical Pharmacology. $6^{\text {th }}$ ed. Jaypee Brothers, New Delhi; 2008:798-800.
12. Dale M. The complete drug reference. $23^{\text {rd }}$ ed. Pharmaceutical Peers. 2002:596-599.

13. Kim HJ, Camilleri M, McKinzie MB, Lempke MB, Burton DD, Thomforde GM, et al. A randomized controlled trial of a probiotic VSL \#s on gut transit and symptoms in diarrhea predominant irritable bowel syndrome. Aliment Pharmacol Ther. 2003;17:895.

14. Naranjo CA, Busto U, Sellers EM, Sandor P, Ruiz I, Roberts EA, et al. A method of estimating the probability of adverse drug reactions. Clinical pharmacology and therapeutics. 1981;30:239-45.

Cite this article as: Jose $\mathrm{P}$, Narayanan PV, Thomas $\mathrm{V}$. A randomised double blind placebo controlled trial to assess the efficacy and tolerability of short course of ornidazole in diarrhoea predominant irritable bowel syndrome. Int J Basic Clin Pharmacol 2018;7:2086-90. 